\title{
BABEL MUlticulturalistA
}

Eneida Maria de Souza

UFMG

\begin{abstract}
RES U M O
A partir do filme Babel, de Alejandro González Iñarritu, o estudo trata dos descompassos da modernização conservadora e desenfreada, que tem como preço a perda dos valores humanitários, em nações que se desintegram e se fragmentam na luta pelo domínio.
\end{abstract}

PALAVRAS - CHAVE

Babel. Multiculturalismo. Modernidade.

A "torre de Babel" não configura apenas a multiplicidade irredutível das línguas, ela exibe um não-acabamento, a impossibilidade de completar, de totalizar, de saturar, de acabar qualquer coisa que seria da ordem da edificação, da construção arquitetural, do sistema e da arquitetônica. O que a multiplicidade de idiomas vai limitar não é apenas uma tradução "verdadeira", uma entre expressão (entre expression) transparente e adequada, mas também uma ordem estrutural, uma coerência do constructum.

Jacques Derrida

A primeira motivação para a escolha do tema deste texto foi o filme Babel, de 2006, do diretor mexicano Alejandro González Iñarritu, com roteiro de Guillermo Arriaga. A sensibilidade no tratamento de questões ligadas a diferentes culturas, a montagem simultânea de cenas enfocando quatro países, os dramas das personagens guiados por fios e conexões inusitadas, representam uma das mais originais perguntas feitas ao mundo neste momento pós-11 de setembro. Sem a pretensão de esgotar a leitura do filme por ter escolhido o viés do multiculturalismo e das diversas modalidades assumidas pelos discursos da modernidade, acredito estar contribuindo para a discussão da complexa rede conceitual construída pela crítica cultural ao longo dos últimos anos.

Muito se tem debatido sobre a natureza precária das noções e conceitos já comuns ao vocabulário das ciências humanas, uma vez que esses dependem das mudanças verificadas no mundo, tanto no âmbito cultural quanto político e econômico. Como exemplo dessa transformação operada nas relações interculturais, o multiculturalismo passou a ser um dos alvos mais atingidos. Isso se deve, principalmente, ao esgotamento dos modelos de reconciliação e aceitação de muitas culturas no interior da nação e à 
necessidade de substituição do conceito de diferença pelo de desigualdade, com vistas a propiciar um sistema de trocas que não fosse unilateral. Com a globalização tecnológica, quase todo o planeta entrou em interconexão simultânea, criando, assim, novas modalidades de diferenças e desigualdades. O livro de Néstor García Canclini, Diferentes, desiguais e desconectados, refaz a trajetória dos estudos culturais, desloca conceitos e justifica a troca do termo multicultural pelo de intercultural, por admitir que o primeiro se pauta pela diversidade de culturas, "sublinhando sua diferença e propondo políticas relativas de respeito, que frequentemente reforçam a segregação". O segundo termo, intercultural e globalizado, "remete à confrontação e ao entrelaçamento, àquilo que sucede quando os grupos entram em relações e trocas. Ambos os termos implicam dois modos de produção do social: multiculturalidade supõe aceitação do heterogêneo; interculturalidade implica que os diferentes são o que são, em relações de negociação, conflito e empréstimos recíprocos". ${ }^{1}$

Embora esteja de acordo com a proposta de Canclini, ao entender que o multiculturalismo é uma ficção estatal tranquilizadora, enquanto que o interculturalismo é a proposta de diversidade projetada não a partir do Estado, mas dos próprios atores dos movimentos sociais, retomo o raciocínio de John Beverley (Subalternidad y representación), ${ }^{2}$ para quem o termo multiculturalismo pode ser também lido segundo o viés do interculturalismo. O que se conclui é a importância de considerar que os conceitos podem também ser reciclados e revistos com base nas diferentes posições dos teóricos, sem a preocupação meio obsessiva de criar expressões que substituem outras. Acrescentaria que Beverley postula, dentro de sua posição de seguidor da teoria subalterna, que

La posibilidad radical del multiculturalismo reside estrictamente en una insistencia constitutiva en la igualdad social. Para decir esto en otras palabras, la insistencia del subalternismo es más sobre la desigualdad que sobre la diferencia, aunque quiere marcar también la manera en que la diferencia es experimentada como desigualdad. ${ }^{3}$

Nesse sentido, ambos defendem os mesmos princípios. Acrescentaria que as categorias relativas ao povo e à multidão, seja conforme teorização de Ernesto Laclau, La razón populista ${ }^{4}$ seja de Paolo Virno, Gramatica de la multitud: para una análisis de las formas de vida contemporánea, ${ }^{5}$ tornam-se imprescindíveis para o entendimento da atualização dessa desigualdade no âmbito do próprio sujeito, visto como internamente fissurado e heterogêneo. Trata-se de dimensionar a proliferação de contradições no seio do povo, entendidas como valores positivos no lugar de problemas, tais como falta de educação, cultura da pobreza etc. Ainda dentro do pensamento de John Beverley, "un nuevo proyecto para 'cambiar la vida' seria la expresión política de este reconocimiento de la heterogeneidad y incomensurabilidad de lo social, sin sentir la necesidad de resolver las diferencias en una lógica unitaria o transculturadora."

${ }^{1}$ CANCLINI. Diferentes, desiguais e desconectados, p. 16-17.

${ }^{2}$ BEVERLEY. Subalternidad y representación, p. 205.

${ }^{3}$ BEVERLEY. Subalternidad y representación, p. 204.

${ }^{4}$ LACLAU. La razón populista, 2005.

${ }^{5}$ VIRNO. Gramatica de la multitud: para una análisis de las formas de vida contemporánea. 
É comum ainda vincular o multiculturalismo a uma série de desdobramentos das minorias, que vão da emergência de grupos sociais até então invisíveis, como as culturas indígenas na América, aos grupos minoritários que, a partir dos anos 1970, começam a adquirir voz e a buscar maior visibilidade. Problematiza-se, por conseguinte, a dimensão do termo cultura, pela desconfiança de atitudes hegemônicas e estatais, dos gastos preceitos de universalidade e igualdade entre os povos e os cidadãos. $\mathrm{O}$ número de migrantes-multidões no mundo aumenta de forma considerável, transformando as metrópoles primeiro-mundistas em verdadeira babel de línguas e de etnias, modificando a geografia das cidades, pelo descentramento contínuo dos lugares, antes distintos e controlados pela senha da inclusão e da exclusão sociais.

O pensamento multiculturalista se inscreve igualmente a partir da dissolução do modelo político do Estado-nação e da desconstrução de parâmetros iluministas legados pela razão moderna. Questiona-se o poder estatal e entra em declínio a hegemonia do pensamento ocidental, um dos responsáveis pela defesa de valores universais de cultura. A soberania das instituições políticas é substituída por um conjunto mais amplo de instituições e de forças sociais. Com a produção de novas tecnologias, da informática e do inevitável crescimento do poder do mercado, se dimensionam as noções de tempo e espaço, assim como das múltiplas feições assumidas pela modernidade. A simultaneidade temporal substitui o tempo teleológico da modernidade, encurtando a distância entre culturas e deslocando pontos fixos e imutáveis. Cria-se a ilusão de ser o mundo uma grande tela de $\mathrm{TV}$, na qual convivem, de forma harmoniosa ou não, uma infinidade de povos, um sem número de olhares estranhos e espantados. No âmbito das relações culturais, o enfoque se torna mais transnacional do que nacional, não só pelo enfraquecimento da ordem estatal, como pelo fortalecimento de uma política de efeitos. As desigualdades sociais aumentam, embora a hegemonia do econômico se revista do discurso igualitário entre os povos.

A tolerância racial, o respeito às diferenças, o empenho pelo fim de preconceitos entre os pares, a solidariedade como possível saída para os embates das crises pelas quais passam os países são argumentos utilizados pelo discurso político como forma de maquiar o multiculturalismo através do lema da diferença. $O$ pluralismo exige condições rígidas de convivência, negociações e diálogos.

No mesmo diapasão, a equivalência entre identidade e nação é, segundo Jesús Martín-Barbero, no ensaio "Globalización y multiculturalidad", o que a multiculturalidade da sociedade atual latino-americana faz desmoronar. Por um lado, a globalização diminui o peso dos territórios e dos acontecimentos fundadores que essencializavam o nacional, e, por outro, a revalorização do local redefine a idéia mesma de nação. Não se pode pensar, portanto, que a identidade seja a expressão de uma só cultura homogênea. $O$ monolinguismo e a uniterritorialidade, que a primeira modernização reassumiu da colônia, esconderam a densa multiculturalidade de que está feito o latino-americano e o arbitrário das demarcações que traçaram o nacional.

\section{Modernidades taRdias}

O modelo ocidental e eurocêntrico das teorias sobre a modernidade foi, por muito tempo, aceito como único, sem que sua hegemonia fosse contestada. Outras experiências 
da modernidade deverão ser observadas, considerando não só o descompasso temporal de sua atualização pelas distintas culturas, como as singularidades múltiplas e divergentes dessa vivência dentro das próprias culturas locais. Pensadores do considerado terceiro mundo têm se empenhado em apontar algumas possíveis saídas para sair ou entrar na modernidade, como assim se expressou um deles. Dotados de um pensamento nômade e de experiência vital em permanente deslocamento, esses autores se apropriam da teorização aprendida pelos discursos hegemônicos para desconstruí-los. A maneira pela qual se rompe com teorias da modernidade se justifica pela emergência no entendimento de novas propostas que talvez contribuam para nortear as indagações do presente. Ao termo pós-modernidade, de caráter geral e pertencente ao universo anglosaxão, são apresentadas outras nomenclaturas, mais condizentes com o pensamento e a realidade de cada cultura enfocada. A pós-modernidade, em toda a sua dimensão e abrangência, não poderá ser analisada sem a reflexão das várias vertentes que compõem o pensamento moderno. Os conceitos legados pelas culturas hegemônicas deverão ser revisitados e acompanhar as transformações políticas e culturais do mundo globalizado.

No próprio continente as ocorrências culturais e artísticas não se realizam de modo homogêneo. Jesus Martín-Barbero, teórico espanhol radicado na Colômbia, introduz, nos estudos da mídia, uma reflexão original - a modernidade descentrada que responde pelas várias temporalidades existentes na recepção das culturas hegemônicas por parte das periféricas. Por isso, a referência às modernidades se faz no plural, pela existência de outro estatuto conceitual. O raciocínio pautado pelo princípio da homogeneidade é substituído pelo da heterogeneidade. São alternativas de definição a respeito do termo pós-moderno, ao se pensar na atual situação da cultura na América Latina. A noção de atraso, por exemplo, se desvincula do teor negativo e se impõe como peça integrante da defasagem temporal, do tardio, do sinal de mais das regiões periféricas. A experiência simultânea do tempo não significa que a realidade dos países periféricos seja similar aos outros, o importante é não pensarmos segundo parâmetros causalistas e progressistas. Na perspectiva de Martín-Barbero, a simultaneidade temporal aponta diferenças. E não se pauta por semelhanças que poderiam colocar a poética sincrônica imune a conotações de ordem contextual e histórica. Outras denominações surgem, como as modernidades tardias, com Fredric Jameson (1996), que trabalha com o capitalismo tardio, e Stuart Hall (1998), com as modernidades alternativas e o conceito de modernidades tardias. Outros preferem denominá-las de modernidades periféricas, modernidades livres (at large), segundo o indiano Arjun Appadurai, em seu livro Modernity at large (2001), ou, como Anthony Giddens (1997), modernidades reflexivas. O lugar dos exilados indianos nos Estados Unidos é analisado por Appadurai para explicar o conceito de modernidades livres, ao serem construídas comunidades imaginadas que se identificam pelos meios de comunicação de massa, como o rádio, a televisão, o rádio, o cinema, sem passar pela experiência das modernidades concebidas pelos órgãos oficiais. A passagem referente ao conceito de modernidade descentrada em Martín-Barbero (2002) é a que se segue:

${ }^{6}$ MARTÍN-BARBERO. Globalización y multiculturalidad, p. 25. 
El inacabado projecto de la modernidad no puede entonces separarse tan nítida y limpiamente de la razón que inspira la modernización como pretende Habermas (El discurso filosófico 13 y ss). De ahí que su crisis comporte para la perifería elementos liberadores. Así la posibilidad de afirmar la "no simultaneidad de lo simultáneo " (Rincón)- la existencia de destiempos con la modernidad que no son pura anacronía sino residuos (en el sentido que esa noción tiene para R. Williams en Marxismo y literatura 144) no integrados de otra economía - que al transtornar el orden secuencial del progreso modernizador libera nuestra relación con el pasado, con nuestros diferentes pasados, haciendo del espacio el lugar donde se entrecruzan diversos tiempos históricos, y permitiéndonos así recombinar las memorias y reapropriarnos creativamente de una descentrada modernidad. ${ }^{6}$

Segundo o teórico, trata-se de uma "descontinuidade de modernidade nãocontemporânea", em que a não contemporaneidade deve ser claramente distinta da idéia de atraso constitutivo, de atraso convertido em chave explicativa da diferença cultural. Seria uma idéia que se manifesta em duas versões. A primeira, apontando que a originalidade dos países latino-americanos, e da América Latina como um todo, dependeu de fatores que se desvinculam da lógica do desenvolvimento capitalista. A segunda, entendendo a modernização como a recuperação do tempo perdido, e portanto identificando o desenvolvimento com o abandono de identidades locais para nos tornarmos modernos. Essa descontinuidade estaria situada em outra chave, ao permitir que se rompa "tanto com um modelo a-histórico e culturalista quanto com o paradigma da racionalidade acumulativa em sua pretensão de unificar e subsumir num só tempo as diferentes temporalidades sócio-históricas".?

\section{BABEL, O FILME}

Tendo em vista a simultaneidade das cenas montadas no filme Babel, com o objetivo de apresentar a atuação de diferentes personagens em distintos países e culturas, embora estejam ligadas por um acontecimento comum, haveria um conceito único de modernidade que os uniria? Qual o grau de semelhança e de diferença entre distintas feições do moderno vivenciado pelas personagens inseridas na vida urbana do Japão, no deserto de Marrocos, na fronteira entre o México e os Estados Unidos? A constatação de ser a película uma das grandes reflexões sobre a tênue fronteira que separa os povos, os seres humanos, sobre um lance do acaso que irrompe e provoca distúrbios incontroláveis, não estaria aí expressa a idéia de uma modernidade global, totalitária e perversa?

A análise do filme se concentra nas diferentes modalidades do conceito de modernidade, na discussão do multiculturalismo como representação contemporânea dos efeitos que a globalização econômica tem provocado na atualidade diante de países tão diferentes do ponto de vista econômico, social, cultural e político. Autor de Amores brutos, de 2000, e de 21 gramas, de 2003, Alejandro González Iñarritu completa a trilogia, em 2006, com Babel, realizando a película com produção mexicana e norte-americana.

O título do filme remete ao mito bíblico, contido no Gênesis, da torre de Babel. A confusão, gerada pela tentativa dos homens construírem uma torre capaz de alcançar o

${ }^{7}$ MARTÍN-BARBERO. Dos meios às mediações, p. 214. 
céu, termina com o impedimento, por deus, de sua construção. A ação, considerada manifestação de soberba da população, resulta no desentendimento entre os homens, que começam, a partir desse momento, a falar idiomas diferentes. $O$ filme trata do tema da incompreensão entre as personagens e entre culturas. Refere-se, ainda, ao sentido intraduzível do título, processo almejado pela política da globalização para facilitar a compreensão entre povos de línguas distintas. Por essa razão, coincide com a fase prébabel, quando a língua era uma só e todos se entendiam. Ironicamente, o título endossa e nega o tema da incomunicabilidade existente no filme, nega e endossa a sintonia criada com o espectador. Torres de Babel, de Jacques Derrida (2002), discorre sobre a intraduzibilidade do nome, a impossibilidade de tradução. O nome é comentado, parafraseado, mas não traduzido. Outra associação merece ser feita entre o filme e as torres gêmeas de Nova York, abatidas pelos muçulmanos, em 2001, acontecimento responsável pelas mudanças significativas no sistema de controle e policiamento da esfera mundial. As torres de Tóquio, apresentadas como ícones da modernização, se configuram para o espectador como a tentativa de vencer, igualmente, pela tecnologia, a aspiração divina de atingir o céu, de demonstrar poderes e desafios do homem diante da máquina. Do ponto de vista arquitetônico, as torres seriam o simulacro do progresso urbano e comercial estadunidense, entendido como espelho das potências pós-modernas.

A montagem simultânea das cenas segue o modelo dos filmes anteriores, em que se processa a narração fragmentada, ao romper com a cronologia tradicional do discurso cinematográfico: após o anúncio da cena, a apresentação rápida das mesmas, volta-se à elucidação do enredo aí suspenso. As fronteiras fílmicas da montagem são abolidas, sugerindo o movimento rápido e dinâmico das ressonâncias da globalização nos variados países, o corte cinematográfico como apropriação das técnicas de captação de notícias televisivas que se realizam no momento real em que estas acontecem. A visão condensada dos acontecimentos dirige o olhar do espectador para a rapidez com que se transita de um lugar a outro do globo, lugares distanciados geograficamente, mas que se aproximam de forma virtual pela ação da câmera. As peças, ao longo da película, vão-se recompondo, como um quebra-cabeças, um jogo de armar, movidas por um fio invisível que comanda o espetáculo, já com cartas marcadas para o resultado e o final do jogo. Os detalhes que associam as cenas entre si são mostradas de forma contrastiva, com o intuito de apontar diferenças de ordem cultural e, ao mesmo tempo, semelhanças de comportamento e desejos inerentes a todo ser humano. No Marrocos, o filho mais novo é o escolhido pelo pai como o mais corajoso e hábil para substituí-lo. É o autor do disparo da espingarda comprada pelo pai de um amigo. Em fase de iniciação sexual, observa, como voyeur, a irmã trocar de roupa, diálogo proibido realizado pela relação esquiva entre olhar e ser olhado. No Japão, a jovem surda-muda ensaia a comunicação difícil com os rapazes pela exibição do corpo, pela experiência das drogas. Em ambas as situações registra-se a incomunicabilidade como tema recorrente, assim como de outras cenas envolvendo outras personagens.

O enredo, de complexa urdidura, pode ser resumido de forma também fragmentada e ser entrecortado por interpretações. A experiência da morte é o tema que congrega todas as cenas. Vivenciada de maneiras diferentes, ela é acompanhada do ritual de iniciação pelo qual as personagens entram no processo de aprendizagem relativa à falta 
e à morte. Para a atualização desse ritual, situações de perigo, isolamento e sofrimento concorrem para a passagem a outro nível, da criança para o adulto, do celibatário para o casado, da natureza para a cultura, da saída da casa paterna para o mundo. O casal de estadunidenses convive com a proximidade da morte iminente, a perda de sangue, a dor, o alívio do sofrimento pela ação da mulher marroquina, silenciosa e que com o remédio, o fumo, revela saídas alternativas e naturais para a cura e a criação de uma relação de afeto entre as pessoas. $\mathrm{O}$ jovem marroquino, ao atingir a estrangeira, é jogado para outro nível de responsabilidade social, confessa ao pai o crime e se esconde dos policiais. A japonesa surda-muda, em fase de iniciação sexual, se entrega ao policial em sua própria casa. Os filhos do casal saem pela primeira vez de casa sem os pais, atravessam a fronteira dos Estados Unidos e entram em contato com os costumes mexicanos durante o casamento do filho da babá, entre eles a degola da galinha, a visão do sangue escorrendo, o convívio com o estranho. E, na volta, a fuga de carro com o sobrinho da babá, pela madrugada, sendo perseguidos pelos guardas e vivenciando a experiência do perigo e da morte. A última imagem das crianças é a do abandono no deserto, na fronteira, entregues ao total desamparo.

A primeira cena do filme, a venda de uma arma por um camponês marroquino, é feita na presença do comprador e dos dois filhos. A arma teria a função de matar os chacais, perigosos adversários das ovelhas. Deflagra os acontecimentos futuros e funciona como elo que interliga as cenas de todo o filme. As quatro narrativas se conjugam, representadas por quatro países, Marrocos, Japão, Estados Unidos e México, e três continentes: América do Norte, África e Ásia. Na primeira cena, a paisagem é o deserto de Marrocos, com suas montanhas e caminhos tortuosos, onde se pratica a pecuária, a criação de ovelhas, atividade passada de pai para filho. O comércio informal é operado por uma economia agrária, pela troca de produtos entre os membros da comunidade. A venda da espingarda irá gerar a corrente futura que culminará com a necessidade de descobrir o primeiro proprietário da arma, para se encontrar o autor do crime. $\mathrm{O}$ ambiente, despojado e aberto, contrasta com a modernidade excessiva de Tóquio, da metrópole pós-moderna, caracterizada pela alta tecnologia do primeiro mundo. Trata-se de um espaço que escapa da racionalidade moderna, dos domínios específicos do Estado-nação, constituindo-se como lugar vazio, capaz de provocar distúrbios inesperados e metamorfoses.

Nesse deserto ocorre a cena que envolve o casal em viagem de turismo em Marrocos, num ônibus que reúne pessoas de várias nacionalidades. O motivo da viagem é extremamente particular, pois serviria para tentar esquecer o drama do casal pela perda do filho mais novo, embora a depressão da mulher e precariedade higiênica do lugar, aos seus olhos, a impedissem de usufruir o passeio. Inconsolável, não se sente bem em Marrocos, e esse sentimento se manifesta pelo alto grau de incomunicabilidade entre eles. O casal de filhos permanece na Califórnia, sob os cuidados da babá, de origem mexicana, que espera a volta dos patrões para ir ao casamento do filho no México, numa cidade fronteiriça com os Estados Unidos. O filho mais novo da família marroquina, ao demonstrar para o irmão sua habilidade no manejo com a arma, uma espingarda Winchester, atira a esmo e por acaso atinge a mulher. Com a ajuda do empregado do ônibus, consegue-se chegar ao povoado onde mora o ajudante.

$\mathrm{Na}$ cidade de Tóquio, com suas torres, prédios iluminados e coloridos, vislumbrase o espetáculo da cidade pós-moderna, luxuosa, marcada por uma cultura heterogênea 
e em confronto com os valores tradicionais. $\mathrm{O}$ apartamento da jovem surda-muda revela o conforto e a natureza limpa e despojada dos interiores, traços do gosto burguês, do excesso de tecnologia que resulta na carência de adornos e enfeites excessivos. A carência se metaforiza nos comportamentos regrados, nos relacionamentos frágeis e na incomunicabilidade entre pai e filha, acentuada após o suicídio da mãe. A jovem se comunica com os outros através de sinais, da escrita e do corpo. O diálogo um pouco efetivo se dá com o porteiro do prédio, mediador entre o fora e o dentro, entre a esfera semidoméstica e a pública. Este lhe passa os recados e possibilita o encontro entre a jovem, a polícia e o pai. Por um jogo espelhado das histórias, a jovem se expõe sexualmente para os rapazes, num gesto de rebeldia, ironia e afastamento. No caso do encontro com o policial, ao se desnudar, e se entregar a ele, o relacionamento, embora estranho e revelador da falta de entrosamento com outras pessoas de seu meio e idade, responde pelo futuro encontro com o pai. A cena representa, entre outras significações, a condensação da figura do pai na do policial, o que motiva a realização do desejo de se unir ao pai, considerando essa união como forma de restaurar o equilíbrio familiar e social. Em Marrocos, a promiscuidade familiar incita o desejo sexual entre irmãos e acende, de forma natural, a sexualidade reprimida, demonstrando a necessidade de romper fronteiras de ordem familiar. Este núcleo se mostra tão fechado, em virtude das poucas opções de conhecimento do outro, que incita à relação incestuosa, o reforço da concepção tradicional de família. Espelhadas igualmente são as situações de perda entre o casal de americanos, ou seja, a perda do filho, e a jovem japonesa, a perda da mãe.

Na Califórnia, outra cena: a babá dos filhos do casal, que se prepara para ir ao casamento do filho no México. Decide levar as crianças à festa, na impossibilidade de deixá-las com alguém, e em virtude da permanência dos patrões em Marrocos. O ritual do casamento, de natureza festiva se associa ainda ao ritual de passagem, não só do ponto de vista das crianças, mas em relação aos noivos. A passagem de um estado civil para outro é comemorada com festa e música, com a presença de amigos e familiares. É o coroamento da concepção de família nos moldes tradicionais. Percebe-se a cena por meio não da economia afetiva, mas do excesso, representado pelo grande número de parentes, de alegria e descompromisso com as ações. O sinal mais evidente do desvio de função relativo aos objetos se verifica no gesto do sobrinho da babá, ao lançar, como sinal de congraçamento, tiros para o alto. Mas a atitude aleatória assumida pelos jovens no deserto resulta em tragédia, pois o disparo em direção ao ônibus de turistas atinge um deles. Na cena mexicana, acredita-se ainda na integração familiar como sustento para a preservação dos valores tradicionais de união e solidariedade. A necessidade de integração da família irá funcionar, no final do filme, como saída um tanto provisória imposta pela incomunicabilidade vivida pelas personagens.

$\mathrm{Na}$ busca pelo proprietário da arma cujo disparo atingiu a mulher, policiais procuram o pai da jovem japonesa. Doada pelo japonês em viagem turística ao Marrocos ao seu guia, este a vende aos pais dos meninos. Na busca em Marrocos pelos criminosos, o jovem confessa ter sido ele o autor dos tiros. No final, a embaixada dos Estados Unidos resgata o casal e a mulher se salva. O possível ato de terrorismo cometido em Marrocos é desfeito pela confissão do jovem que, de mãos erguidas, num gesto de clemência e desespero, admite ter sido ele o autor do disparo. 
O drama vivido pelas personagens retoma o drama existencial e político contemporâneo, no qual o acaso é o deflagrador dos acontecimentos, no lugar de uma ação premeditada e objetiva. $\mathrm{O}$ acaso, as coincidências e a impossibilidade de controle das situações traduzem a imprevisibilidade da sociedade contemporânea. Aquilo que não se pode prever. Assim, quanto mais controle estatal, mais se constata a presença das linhas de fuga, da inserção do outro no sistema. O sentimento de culpa, mesmo tendo sido assumido pelo jovem, deixa de ser um dado a ser considerado pelo espectador, da mesma forma que o autor do crime não é o primeiro possuidor da arma, uma vez que se dissolve a idéia de relação entre o crime e o proprietário da arma, pelo descontrole que o objeto e a sua trajetória acarretam. A arma entra no sistema simbólico e abstrato das trocas. Rompe-se com a relação de causa-efeito, em virtude de não existir uma causa premeditada do crime. Os proprietários da arma e os autores do crime perdem a função a eles atribuída. Essa responsabilidade é parte do sistema, com sua perversidade e o caráter aleatório das ações, atitudes próprias do descontrole que se processa em cadeia. A gratuidade das ações provoca o efeito dominó, o efeito bola de neve, à semelhança do processo de globalização, onde uma ação acontece em determinado país e ecoa nos outros de forma imediata. Tiros trocados entre a família de Marrocos e os policiais entram no processo de descontrole e começam a liquidar inocentes. As invasões dos Estados Unidos no Afeganistão e no Iraque confirmam essa gratuidade das ações, o jogo perverso que desloca a culpa do sistema político hegemônico para as sociedades consideradas atrasadas e movidas pela irracionalidade.

As situações de total impotência diante das leis são vivenciadas pela babá mexicana, presa na fronteira do México com os Estados Unidos por estar ilegalmente no país, e pelo autor dos disparos, no Marrocos. A babá, em plena zona desértica, reduplica a função da patroa, ao perder as crianças que estavam sob sua guarda, perde o emprego e a possível cidadania americana. O espaço da punição é o deserto mexicanoestadunidense, fronteira que marca o signo da indecisão e do heterogêneo. Entendido como espaço de exceção, de perigo, de diferença em relação aos espaços urbanos, a fronteira separa territórios, apresentando-se como espaço livre para se cumprir qualquer tipo de lei. Em ambos os lugares, o deserto marroquino e o de fronteira, cria-se um estado de exceção - a vida nua, segundo interpretação de Giorgio Agamben, o homo sacer - situação quando o criminoso não tem com o que defender e é julgado sem escrúpulos, por não ter igualmente direito de defesa. Quando julgado por um delito, o homem sacro pode ser morto sem que isso constitua um homicídio, ou execução, ou condenação. Campos de concentração, prisioneiros acusados de terem realizado ações terroristas, infrações às leis de imigração, todas essas situações são interpretadas como perigosas e duvidosas. Ao serem envolvidas nessas tramas, as pessoas perdem tudo, ficando à mercê de qualquer tipo de lei a ser aí aplicada: "O estado de exceção, logo, não é tanto uma suspensão espaço-temporal quanto uma figura topológica complexa, em que não só a exceção é a regra, mas até mesmo o estado de natureza e o direito, o fora e o dentro transitam um pelo outro. É justamente nesta zona topológica de indistinção, que deveria permanecer oculta aos olhos da justiça, que nós devemos tentar fixar o olhar". 8

${ }^{8}$ AGAMBEN. Homo sacer. O poder soberano e a vida nua, p. 43. 
As observações finais desta análise são dirigidas ao encontro das personagens que se unem pelo afeto, pela criação de um elo comum que rompe com o comportamento usual, reintegra o relacionamento e desconstrói imposições de âmbito racional e distanciado. A mulher se entrega ao marido num gesto afetivo quando é por ele ajudada a fazer as necessidades fisiológicas. Ou quando o seu sofrimento físico é aliviado pelas artes da mulher marroquina, aproximação que se realiza pela aspiração do fumo, da substância por ela preparada. A união da família de origem marroquina se realiza, ironicamente, pela dor da morte do filho mais velho, obrigando o outro a se confessar. $\mathrm{O}$ encontro no alto da varanda do apartamento, em Tóquio, da jovem com o pai, com vista para a paisagem noturna e iluminada, sugere o início da conquista desse afeto perdido. São os descompassos da modernização conservadora e desenfreada, apresentados nas suas inúmeras dimensões e diferenças, o preço a pagar pela perda de valores humanitários, submersos na guerra cotidiana do trabalho e da racionalidade. Babel representa cenas alegóricas que remetem tanto para as desigualdades e descompassos entre os povos quanto para a imagem do acaso como estratégia para a dominação do mundo pelos países que ainda impõem seu poder hegemônico diante dos países periféricos. Nações que, contudo, se desintegram e se fragmentam na luta pelo domínio cego das demais.

\section{A \\ A B STRACT \\ Using Alejandro González Iñarritu's movie Babel as a starting point, this paper examines the discordances of conservative and unbridled modernization that causes the loss of humanitarian values in nations that disintegrate and collapse in the fight for dominion.}

\section{KEYWORDS}

Babel. Multiculturalism. Modernity.

\section{REFERÊNCIAS}

AGAMBEN, Giorgio. Homo sacer: o poder soberano e a vida nua. Belo Horizonte: Editora UFMG, 2002.

APPADURAI, Arjun. La modernidad desbordada - dimensiones culturales de la globalización. Buenos Aires: Fondo de Cultura Económica, 2001.

BEVERLEY, John. Subalternidad y representación. Madrid: Iberoamericano, 2004.

CANCLINI, Néstor Garcia. Diferentes, desiguais e desconectados. Trad. Luiz Sergio Henriques. Rio de Janeiro: Editora UFRJ, 2005.

DERRIDA, Jacques. Torres de Babel. Trad. Júnia Barreto. Belo Horizonte: Editora UFMG, 2002. 
GIDDENS, Anthony; BECK, Ulrich; SCOTT, Lash. Modernização reflexiva. Política, tradição e estética na ordem social moderna. São Paulo: Editora UNESP, 1997.

HALL, Stuart. A identidade cultural na pós-modernidade. Rio de Janeiro: DP\&A, 1998.

JAMESON, Fredric. Pós-modernismo - a lógica cultural do capitalismo tardio. Trad. Maria Elisa Cevasco. São Paulo: Ática, 1996.

LACLAU, Ernesto. La razón populista. Buenos Aires: Fondo de Cultura Económica, 2005.

MARTÍN-BARBERO, Jesús. Dos meios às mediações. Rio de Janeiro: Editora UFMG, 1997.

MARTÍN-BARBERO, Jesús. Globalización y multiculturalidad: notas para una agenda de investigación. In: MORAÑA, Mabel (Ed.). Nuevas perspectivas desde/sobre América Latina: el desafío de los estudios culturales. Santiago: Cuarto propio. 2002. p. 19-34

VIRNO, Paolo. Gramatica de la multitud: para una análisis de las formas de vida contemporánea. Madrid: Traficantes de sueños. 2003. 